\title{
Sebaceous hyperplasia of labium major: Histopathological images
}

\section{Chidambharam Choccalingam ${ }^{1}$, Shivakumaran Gurusamy ${ }^{1}$, Premila Samuel ${ }^{2}$}

${ }^{1}$ Department of Pathology, SRL Ltd, Chennai, India, ${ }^{2}$ Lab Head, Labolathory, SRL Ltd, Chennai, India

Corresponding author: Dr. Chidambharam Choccalingam, E-mail: chidambharam@gmail.com

A 29 year old female presented with swelling in the right labium major for a period of 2 months. Gynaecological examination revealed a soft, non tender, skin covered polypoidal swelling measuring $2 \times 2 \mathrm{cms}$ at the right labium major (Fig. 1). An elective excision biopsy was performed. Gross examination showed a skin covered polypoidal tissue with underlying multiple yellow popular areas and with central depression. On microscopy, enlarged sebaceous gland composed of numerous lobules ( $>4$ lobules) grouped around a centrally located sebaceous duct. Most of the sebaceous gland lobules appeared mature (Fig. 2). The cells had vesiculated cytoplasm and central nucleus with no atypical features (Figs. 3a and b). Overlying epidermis did not have any pathological feature. No atypia or necrosis or mitosis was seen. With the morphological features a diagnosis of sebaceous hyperplasia of labium major was made.

Sebaceous glands are present throughout the skin except the palms and soles [1]. Sebaceous hyperplasia is commonly seen in the face and less frequently seen in the chest, ocular caruncle, penis, scrotum and vulva [2]. Though, no definite criteria available for diagnosis of sebaceous hyperplasia, sebaceous gland hyperplasia has been defined as the presence of $>4$ sebaceous lobules attached to the infundibulum of each pilosebaceous unit $[1,3]$. Sebaceous hyperplasia of vulva differs from their counterparts arising in the face, by having almost always a polypoidal presentation; larger size and affecting a younger age group [1]. The clinical differential diagnosis includes condyloma acuminate and vulval neoplasms, while the histopathological differential diagnosis includes ectopic sebaceous glands and sebaceous

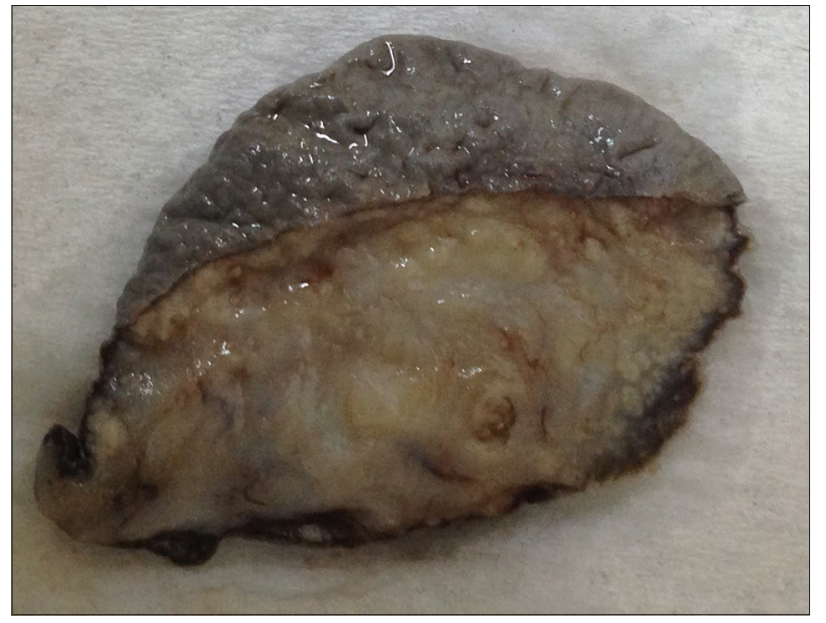

Figure 1: Polypoidal skin covered tissue with underlying yellow papular areas.

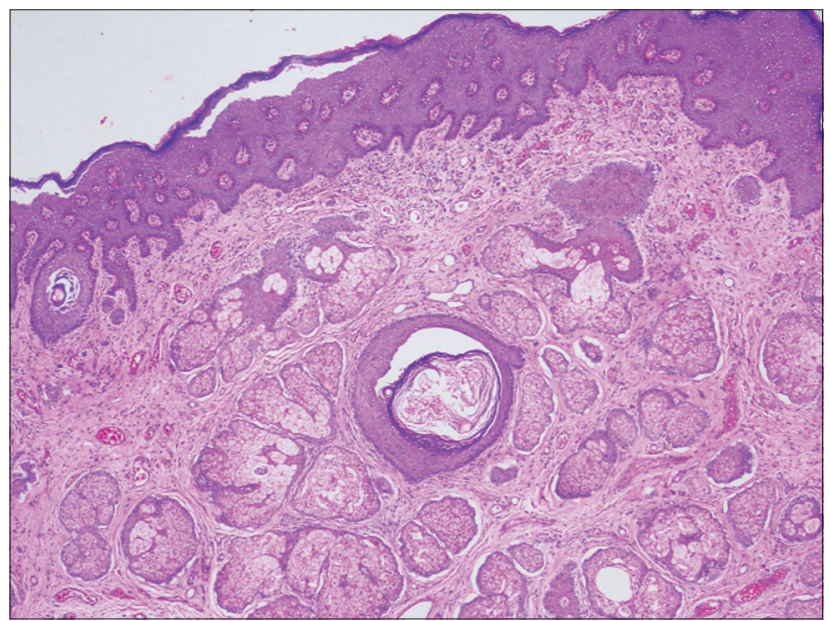

Figure 2: Numerous lobules of sebaceous glands around pilosebaceous unit (H\&E x 10).

adenoma [1]. Sebaceous hyperplasia has more than 4 lobules around pilo-sebaceous units; whereas ectopic

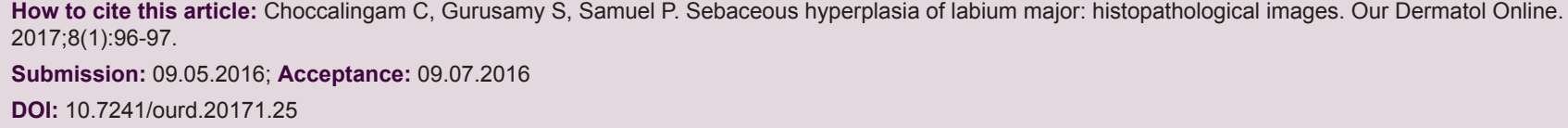




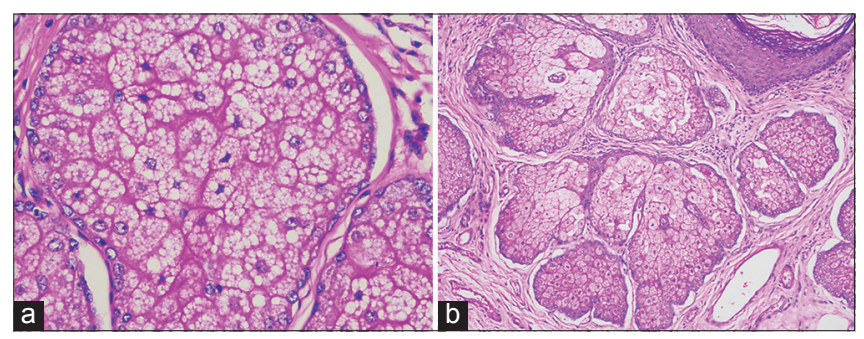

Figure 3: ( $a$ and b) Cytologically the cells show vesicula ted cytoplasm and central nucleus with no atypical features (H\&E x 40).

sebaceous glands have sebaceous lobules without attached follicles; sebaceous adenoma has lobules with predominantly basaloid cells with interspersed mature sebaceocytes [4]. Surgical excision is curative [5], as in our case which had no recurrence after a period of 2 years follow up.

\section{REFERENCES}

1. Daraji WI, Wagner B, Ali RBM, McDonagh AJG. Sebaceous hyperplasia of the vulva: a clinicopathological case report with a review of the literature. J Clin Pathol. 2007;60:835-7.

2. Calonje E, Brenn T, Lazar A. Mckee's Pathology of skin with clinical correlation. 4 ed2012.

3. Yavuza E, Celikb H, Kokcub A, Süllüc Y. Sebaceous gland hyperplasia of vulva: A case report. J Exp Clin Med. 2012;29:231-3.

4. Rao ACK, Nayal B, Gopal SM, Valliathan M, Shenoy R. Sebaceoma of the lip originating in Fordyce's spot - A rarity. Our Dermatol Online. 2016;7:48-50

5. Brzezinski P, Chiriac A. Sebaceous hyperplasia in neonates and adults. Our Dermatol Online. 2015;6:107-8.

Copyright by Chidambharam Choccalingam, et al. This is an open access article distributed under the terms of the Creative Commons Attribution License, which permits unrestricted use, distribution, and reproduction in any medium, provided the original author and source are credited.

Source of Support: Nil, Conflict of Interest: None declared. 